\section{EL SENTIDO DEL ARTE CONTEMPORÁNEO. A PARTIR DEL TRABAJO DE JEAN-LUC NANCY}

\section{DANIEL ALVARO}

UBA/CONICET/Paris 8

Resumen: Durante las últimas dos décadas fue patente la emergencia de reflexiones estéticas novedosas. La irrupción de dichas reflexiones resulta indisociable de la disputa abierta por las creaciones artísticas contemporáneas. La mayoría de los autores que en los últimos tiempos teorizaron sobre esta disputa se vieron obligados a responder del arte, a pensar y decir qué es el arte. En este trabajo me propongo analizar la perspectiva adoptada por Jean-Luc Nancy. El análisis se articula en torno a cuatro cuestiones sobre las que Nancy vuelve una y otra vez en sus textos sobre arte: el sentido de la expresión "arte contemporáneo", la pluralidad de las artes, la diferencia entre el sentido sensible y el sentido inteligible, y las figuras del fragmento, del vestigio y del gesto.

Palabras clave: Jean-Luc Nancy, arte contemporáneo, singular-plural, sentido(s)

Abstract: During the last two decades, it was patent the emergency of novels aesthetic reflections. This irruption results inseparable of the open dispute regarding the contemporary artistic creations. The majority of the authors that have theorized about such dispute in the last two decades have seen themselves compelled to answer on art, to think and to say what art is. In this work I propose to analyze the perspective adopted by Jean-Luc Nancy. The analy- sis is articulated around four issues on which Nancy goes back over and over again in his texts on art: the sense of the expression "contemporary art", the plurality of arts, the difference between the sensitive sense and the intelligible sense, and the figures of the fragment, the vestige and the gesture.

Keywords: Jean-Luc Nancy, contemporary art, singular-plural, sense(s)

Résumé: Durant ces deux dernières décennies, de nouvelles réflexions esthétiques ont émergé. L'irruption de ces réflexions est indissociable du poraines. La plupart des auteurs qui ont théorisé à partir de ce débat se sont vu obligés de répondre de l'art, de penser et de dire ce qu'est l'art. Dans ce travail je me propose d'analyser la perspective adoptée par Jean-Luc Nancy. L'analyse s'articule autour de quatre questions sur lesquelles Nancy revient à plusieurs reprises dans ses textes sur l'art: le sens de l'expression « art contemporain », la pluralité des arts, la différence entre le sens sensible et le sens intelligible, ainsi que les figures du fragment, du vestige et du geste.

Mots-clés: Jean-Luc Nancy, art contemporain, singulier-pluriel, sens débat qui anime les créations artistiques contem-
The sense of the contemporary art. Starting out from the work of JeanLuc Nancy

Le sens de l'art contemporain. A partir du travail de Jean-Luc Nancy
Ponencia leída el 4 de abril de 2013 en el Coloquio Internacional: perspectivas en torno al arte contemporáneo que tuvo lugar en el Museo de Arte Contemporáneo de Salta, República Argentina.
BIBLID [(2015), 5; 123-134]

Recep.: 05/07/2014

Acept.: 18/09/2014 
Nada ni nadie parece estar en condiciones de asegurar un sentido para lo que llamamos, no sin cierta perplejidad, "arte contemporáneo". Se trata, en efecto, de un terreno donde ninguno de los involucrados en el proceso que lo hace posible pisa sobre seguro. Lejos de lo que podría creerse, esta inseguridad o, si se prefiere, esta vacilación de sentido que todos compartimos, no es obstáculo para la continua expansión de las prácticas creativas y de las distintas actividades ligadas al arte contemporáneo.

Con frecuencia se admite que el arte de hoy en día es rebelde al sentido. Incluso hay quienes afirman que esta rebeldía del arte respecto del sentido es, de manera paradójica, lo que define su sentido. Esta paradoja se puede analizar de distintas maneras. En cualquier caso, hay que evitar confundir un pensamiento de este tipo con aquel otro que proclama la simple y llana insensatez del arte. Esta última proclama, que crece como un rumor sordo y por momentos ensordecedor, suele formar parte de una demanda generalizada cuyo alcance excede largamente los debates puntuales sobre el sentido del arte contemporáneo. Se trata de la demanda de sentido en un mundo que, según se dice y se repite sin cesar, ya no tiene sentido. Para muchos de los que anhelan un tiempo pleno de certezas y declaran vivir en un tiempo que ha perdido todo sentido, no hay nada extraño en que el arte correspondiente a este tiempo sea también él un arte sin sentido.
Pues bien, es contra semejante interpretación que quisiera hablar. Partiendo de la premisa general de este coloquio según la cual hoy nos enfrentamos a una variedad de perspectivas en torno al arte contemporáneo, decidí hablar a partir de una de ellas, una que vale la pena escuchar precisamente por lo que tiene para decir sobre el sentido -en todos los sentidos de la palabra "sentido"- en un momento en que ya ni siquiera se intenta pensarlo o experimentarlo. Me refiero a la perspectiva que desde hace al menos dos décadas se despliega en las intervenciones de Jean-Luc Nancy. ${ }^{1}$

\section{El "arte contemporáneo"}

El arte y las artes siempre ocuparon un lugar destacado en la obra de Nancy, aunque es evidente que en el transcurso de los últimos años estos temas ganaron presencia en el conjunto de su producción filosófica. ${ }^{2}$ Desde la publicación en 1978 de El absoluto literario junto a Philippe Lacoue-Labarthe, puede decirse que nada de lo relativo al arte le es ajeno. ${ }^{3}$ Sus intervenciones en este campo incluyen desde análisis eruditos sobre el concepto de "arte" donde se discute con algunos de los representantes más encumbrados de la tradición filosófica occidental, hasta observaciones puntuales sobre literatura, pintura, cine, música y danza, por sólo nombrar las artes que más visiblemente han captado su interés.

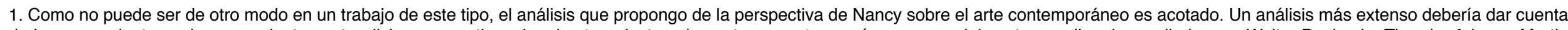
de los cruzamientos y descruzamientos entre dicha perspectiva y las de otros destacados autores contemporáneos, especialmente aquellas desarrolladas por Walter Benjamin, Theodor Adorno, Martin

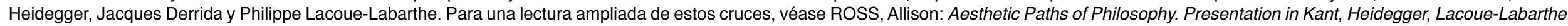
and Nancy. Stanford, Stanford University Press, 2007.

a . Nruncy. Stanford, Stanford University Press, 2007. reciente de este tipo de eventos es el "Il Congreso de Estética y Política: En torno al pensamiento de Jean-Luc Nancy", celebrado en mayo de 2013 en la Universidad Politécnica de Valencia.

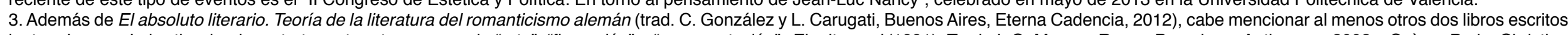

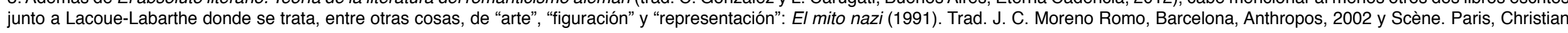
Bourgois, 2013. 
Un punto a destacar es que en relación a otros filósofos contemporáneos dedicados a la reflexión estética, Nancy tiene una relación pública más directa con la práctica artística. Lo cual se evidencia en su propia escritura antes que en cualquier otra parte. Sobre todo, Nancy es un escritor. El hecho de que prácticamente todos sus libros publicados hasta el momento traten en mayor o menor medida asuntos filosóficos no cambia en nada las cosas. En sus textos articula estilos y géneros totalmente ajenos el gran canon de la filosofía sin que ello signifique reducir en lo más mínimo las exigencias de la práctica filosófica. Incluso me atrevería a decir que algunos de sus escritos más bellos - pienso aquí, por ejemplo, en los fragmentos que conforman su libro Corpus - participan de una cierta experiencia poética. Pero eso no es todo. Independientemente de la cuestión de la mezcla de estilos y géneros en la escritura de Nancy, cuyo desarrollo exige naturalmente un análisis aparte, aquel mantiene una relación fluida con el mundo del arte. Son conocidos sus intercambios con artistas de áreas diversas. Sin ir más lejos, vale recordar las recientes colaboraciones con la bailarina y coreógrafa Mathilde Monnier plasmadas en una serie de publicaciones y en obras que contaron con la intervención del propio filósofo en escena.

Con todo esto quiero decir que no es un filósofo que se ocupe del arte en el sentido habitual de la expresión. Parece más bien un filósofo ocupado por el arte, habitado no solamente por inquietudes filosóficas dirigidas al arte, sino también por inquietudes artísticas indisociables de su propia filosofía. Esta singularidad, que a su vez lo distingue como pensador, resulta de la mayor importancia cuando se intenta comprender el alcance de sus reflexiones sobre el arte en sentido amplio.
Para empezar conviene aclarar qué entiende Nancy por la expresión "arte contemporáneo". Dicha expresión no tiene nada de evidente y esa es una de las razones por las que estamos acá. Hablar de "arte contemporáneo" es hablar de un problema y creo que, más allá de las diferencias teóricas que puedan existir entre quienes hoy intentan pensar el tema, esta es una opinión ampliamente compartida. En una conferencia de 2006, titulada "EI arte hoy", Nancy decía:

"Hoy, ¿qué hay del arte? ¿Qué sucede hoy con el arte? En principio sucede que, justamente, ha sido creada y empleada esta categoría de arte contemporáneo y que esta categoría hace surgir inmediatamente toda una serie de problemas, puesto que el arte siempre ha sido contemporáneo de su tiempo. Miguel Ángel es contemporáneo, Praxíteles es contemporáneo, el pintor de Lascaux es contemporáneo de sus contemporáneos, ¿cómo un artista podría no ser contemporáneo? Puede no serlo, sin duda, solamente a condición de salir de alguna manera del arte, es decir que si hoy alguien ejecuta un cuadro a la manera de Poussin o de Renoir, no será contemporáneo, ni siquiera será contemporáneo de Renoir o de Delacroix, no será contemporáneo de nadie, de alguna manera estará repitiendo formas. Comprendemos, pues, que el arte siempre es contemporáneo porque pertenece a una creación de formas en el espacio de lo contemporáneo, en el espacio de una actualidad, y que en esta actualidad el arte da a sentir, a ver, en principio, si hablamos de las artes plásticas."

Una obra de arte reciente llamaba la atención sobre esta misma cuestión. Me refiero al neón de Maurizio Nannucci colgado en la fachada del Altes Museum de Berlín, donde podía leerse la siguiente frase: All Art Has Been

4. "L'art aujourd'hui", conferencia dictada el 22 de marzo de 2006 en la Accademia di Belle Arti di Brera, en Milán. Traduzco directamente de la transcripción original en francés hasta ahora inédita. En una versión ligeramente distinta, esta conferencia apareció bajo el título, "L'arte, oggi", FERRARI F. (ed.): Del contemporaneo. Saggi su arte e tempo. Milano, Bruno Mondadori, 2007, pp. 1-20. 
Contemporary. Todo arte ha sido contemporáneo: puesta en juego y puesta en abismo del problema. Nada resulta más fácil y al mismo tiempo más difícil de asimilar que esta frase escrita en grandes letras de neón anaranjado sobre la puerta de entrada a un museo de antigüedades clásicas. Ahora bien, si todo arte ha sido contemporáneo, como sentencia la obra de Nannucci, cabe preguntarse cuál es la especificidad de lo que hoy llamamos de esa manera. Dicho de otro modo: ¿en qué se diferencia nuestro arte contemporáneo, el de nuestro aquí y ahora, del de otros espacios y otros tiempos?

En cada tiempo y en cada espacio, el arte es eso que ante todo "da a sentir". Y lo que el arte da a sentir según Nancy es "una cierta formación del mundo contemporáneo, una cierta puesta en forma, una cierta percepción de sí del mundo". Dar a sentir, pues, es lo propio del arte. Si acaso el "arte contemporáneo" sigue siendo "arte", lo que el arte da a sentir en la actualidad es la forma actual del mundo. En cualquier caso, semejante afirmación no dice nada específico sobre el arte actual, y por lo tanto, tampoco dice nada sobre la forma del mundo en la actualidad. Para Nancy, el rasgo distintivo del arte contemporáneo es que habilita una discusión de largo alcance en torno a la pregunta o la cuestión del arte. Entre otras cosas, el arte contemporáneo da a sentir la necesidad acuciante de interrogar el arte. Dice Nancy: "El arte hoy es un arte que, antes que otra cosa, pregunta '¿qué es el arte?'; en consecuencia, es un arte que pregunta cómo es posible y cómo es deseable dar una forma al mundo". La palabra "forma" debe entenderse aquí en un sentido muy amplio. Por ejemplo, Nancy habla de "formas visuales" pero también habla de "formas sonoras" y de "formas verbales"... Lo que me parece importante retener es que desde esta perspectiva las formas del arte contemporáneo, a diferencia de las formas del arte precedente, no están dadas previamente. En este sentido afirma Nancy que "quizás la tarea del arte hoy es deber proceder sin ningún esquema, sin ningún esquematismo". No es casual que el arte de hoy deba proceder así puesto que habitamos un mundo que gradualmente ha ido perdiendo los modelos que hasta hace poco regulaban los diferentes ámbitos de la existencia social. Habitamos un mundo cuyo sentido, por ser desconocido, nos es inaudito, y es eso de lo que el arte contemporáneo viene a dar cuenta.

La pregunta por el arte supo plantearse de modos muy diferentes a lo largo de la historia. Evidentemente, no es nueva. Lo que representa una novedad y una verdadera contradicción es que hoy la pregunta por el sentido del arte nace del desacuerdo fundamental sobre el estatuto artístico de las obras pertenecientes al llamado arte contemporáneo. Precisamente porque no existe consenso sobre el hecho de que dichas obras sean obras de arte es que la necesidad de volver a preguntar "¿qué es el arte?" se ha vuelto apremiante desde hace varias décadas.

La contradicción inherente al estado de cosas actual se puede resumir del siguiente modo: el sentido del arte contemporáneo reside en abrir la disputa por el sentido del arte. Ahora bien, esta disputa por momentos furibunda no se agota en las discusiones sobre la artisticidad de las obras. También ha dado lugar a interesantes y novedosos planteos a propósito del concepto de arte. Muchos de los autores que en los últimos tiempos reflexionaron sobre esta disputa se vieron obligados a responder del arte, a pensar y decir qué es el arte. Así lo hicieron, por mencionar algunos autores renombrados, Jean-Louis Déotte, Georges Didi-Huberman, Jacques Rancière y Nancy. A continuación voy a intentar glosar, breve y esquemáticamente, la respuesta de este último.

\section{El arte y las artes}

Para decirlo de una vez y que no queden dudas al respecto, la respuesta de Nancy a la pregunta por el arte supone una ontología. Como se verá, la 
cuestión del ser o la esencia del arte, vieja cuestión que atraviesa la historia de las teorías estéticas occidentales desde Platón hasta Heidegger incluido, toca también a la teoría de Nancy. De un punto al otro de su pensamiento se percibe una inquietud persistente por la tan mentada esencia del arte. Sobre todo, hay que evitar interpretar este gesto como una regresión o una simple ingenuidad filosófica. Más bien es todo lo contrario. Se trata, justamente, de un gesto -en el sentido preciso que Nancy reserva a esta palabra y sobre el cual diré algo antes de terminar-, un gesto, pues, que hace lo imposible por sensibilizar a los lectores respecto de lo que hay de esencialmente inesencial en el arte.

De los numerosos escritos que Nancy dedica a esta cuestión quisiera hacer referencia a algunos de los textos incluidos en Las Musas, probablemente uno de sus libros más conocidos y hasta el momento su principal aporte al pensamiento contemporáneo sobre el arte. El primero texto al que voy a referirme, y el que abre el libro, se titula "¿Por qué hay varias artes y no una sola? (Conversación sobre la pluralidad de los mundos)". El título es ya una pregunta, ya una respuesta. Desde antes de comenzar, el lector debe enfrentar esta verdad a la vez simple y sumamente problemática: no hay el arte, en singular, sino las artes, en plural. Por si hace falta recordarlo: "Son las Musas, no la Musa". 5

La pluralidad de las artes es aquí el punto de partida y, como intenta demostrar Nancy, lo impensado de los discursos sobre el arte. Desde la antigüedad las artes se clasifican y se jerarquizan. Desde entonces, también, se suele presentar a las artes (clasificadas, jerarquizadas) como manifestaciones de una única esencia del arte. Para Nancy, éstas son las dos maneras más habituales de evitar pensar el origen múltiple de las artes. El hecho de que se admita la existencia de una pluralidad de artes, no quiere decir que esta pluralidad haya sido efectivamente pensada. No se trata, pues, de afirmar una esencia del arte - ni siquiera del modo radical en que lo hace Heidegger-, pero tampoco se trata de afirmar una esencia de las artes. En el fondo, estas alternativas conducen por caminos diferentes a un pensamiento donde la diversidad de las artes queda subsumida a la unidad esencial del Arte. Desde esta perspectiva, entonces, no es cuestión de postular una esencia del arte ni una esencia de las artes. Se trata, más bien, de pensar y decir lo plural como esencia: "lo singular plural del arte, de las artes".

La ontología del ser singular plural es una apuesta de larga data en la obra nancyana. Vale aclarar que no surgió como una cuestión directamente relacionada con el arte. Si esta ontología toca al arte y a las artes es ante todo porque toca a la existencia. O bien, la existencia, el existir de todo lo existente, es eso mismo que toca a la ontología. De momento bastará con decir que se tocan, que se afectan mutuamente, que la una no es ni puede ser indiferente a la otra. Esta relación recíproca entre algo en apariencia tan abstracto como la ontología y la existencia concreta de todos y cada uno de los existentes es, precisamente, lo que Nancy nos hace descubrir. Concretamente, lo que descubrimos es que la existencia es singular y plural. No hay existencia "en general" como no hay existencia previa a las existencias singulares y plurales. "Lo que existe, sea lo que sea, porque existe co-existe". ${ }^{6}$ La existencia es siempre con otros existentes: la existencia es co-existencia. O para decirlo de un modo aún más perentorio: la co-existencia es condición de la existencia.

No es mi intención detenerme ni extenderme demasiado en esta intrincada cuestión. Sin embargo, antes de volver al tema que nos convoca quisiera

5. NANCY, J.-L.: “¿Por qué hay varias artes y no una sola? (Conversación sobre la pluralidad de los mundos)”, Las Musas (1994, 2001). Trad. H. Pons, Buenos Aires, Amorrortu, 2008, p. 11. 6. NANCY, J.-L.: Ser singular plural (1996). Trad. A. Tudela Sancho, Madrid, Arena, 2006, p. 45. 
leer un pasaje donde Nancy escribe lo esencial de su comprensión del "ser singular plural", un pasaje que quizás permita entender mejor la estrecha relación entre esta apuesta ontológica y "lo singular plural de las Musas".

\begin{abstract}
"El ser es singular y plural, a la vez, indistintamente y distintamente. Es singularmente plural y pluralmente singular. Esto mismo no constituye un predicado particular del ser, como si fuera o como si tuviera un cierto número de atributos, entre los cuales este, doble, contradictorio o quiasmático, de ser singular-plural. Lo singular-plural (o: lo singular plural) forma al contrario la constitución de esencia del ser: una constitución que deshace o que disloca en consecuencia, toda esencia única y substancial del ser mismo. Esto no es, sin embargo, más que una manera de hablar, ya que no hay ninguna substancia previa que viniera a ser disuelta. El ser no pre-existe a su singular plural. Más exactamente, no preexiste en absoluto, como nada preexiste: solo existe lo que existe."7
\end{abstract}

Justamente, lo que existe son las artes, las obras y las prácticas artísticas. Existen los artistas, los individuos que forman el público, y los espacios de exposición donde todos se cruzan. Lo que no existe ni preexiste es el Arte entendido como unidad indivisa, esencial y absoluta. Lo singular-plural de las artes desarma la clásica oposición metafísica entre, por un lado, la supuesta esencia del arte y, por el otro, sus respectivas manifestaciones artísticas. Parafraseando a Nancy se puede decir: el arte no pre-existe a su singular plural. Si cabe hablar del arte, incluso del arte contemporáneo, es porque existen las artes, irreductiblemente singulares plurales.

Parecería que ahora estamos en mejores condiciones que al comienzo para responder a la pregunta inicial: ¿por qué hay varias artes y no una sola?
Sencillamente porque tal es el régimen de todo lo que hay o de todo lo que existe: ser varios, de a varios o entre varios. Lo que obstinadamente llamamos "arte", en singular, no podría ser uno consigo mismo, como nada ni nadie en el mundo podría serlo. Las artes son múltiples desde el origen y múltiple es el origen mismo. En realidad, por la misma razón que ya no conviene hablar de un solo arte, tampoco conviene hablar de un solo origen. No solamente ya no conviene, sino que proposiciones semejantes ya no se sostienen. De aquí en más, "arte" y "origen" se dicen en plural. De lo contrario, se corre el riesgo de confirmar una vez más el clásico discurso filosófico sobre el origen-uno del arte-uno, cuando de lo que se trata, en verdad, es de exponer la existencia múltiple de los orígenes y las artes, cada uno y cada una, cada vez singulares.

La misma pregunta se podría responder también con el título de otro de los textos incluidos en Las Musas: "Las artes se hacen unas contra otras". Allí se lee: "las artes nacen de una relación mutua de proximidad y exclusión, de atracción y repulsión, y sus obras respectivas actúan y se sustentan en esa doble relación". ${ }^{8}$ Esto quiere decir que la existencia de las artes, y por lo tanto la posibilidad de algo así como "el arte", depende de una relación que es contemporánea al advenimiento de cada una de las artes. Esta relación recíproca y ambigua entre las artes es a su vez constitutiva: las artes nacen las unas "con" y "contra" las otras.

"Desde el punto de vista del nacimiento o la constitución de las artes, esta tesis significa que las prácticas artísticas, en su disparidad (de la poesía al video, de la performance a la música, del arte povera al body art, etc.), no surgen de un fondo o una identidad común que sea 'el arte', sino que esa identidad - acaso inhallable - sólo está formada por el conjunto de las

7. Ibid., p. 44.

8. NANCY, J.-L.: "Las artes se hacen unas contra otras", Las Musas, op. cit., p. 137. 
prácticas en sus diferencias, sin que ese "conjunto" suprima, por poco que sea, su heterogeneidad. En cierto modo, 'el arte' en singular nunca se da sino a posteriori, y sin duda sólo durante el tiempo de la reflexión de su concepto, pero no en el lapso de su efectividad (en la ejecución o el goce de la obra nos situamos en la pintura, en la música, pero no 'en el arte')."

Si es posible hablar del "arte", es sólo como consecuencia de la existencia de las artes. En este sentido dice Nancy que se da a posteriori. Su permanencia, además, está limitada al tiempo en que se reflexiona sobre él. El arte dura lo que dura el pensamiento que lo piensa. Una vez que se deja de pensar en el concepto "arte", éste desaparece. Esto no significa que no exista un goce del concepto. Existe, ciertamente, y sería un error subestimarlo, sobre todo cuando se trata del arte contemporáneo. Pero entiendo que el "goce de la obra" del que se habla aquí - sea el goce del artista que la ejecuta o del individuo que se expone a ella - apunta a otro sentido. Apunta, precisamente, a uno de los sentidos posibles de la palabra "sentido". En todo caso, apunta más bien en dirección al sentido sensible que al sentido inteligible. Aunque como se verá enseguida, esta diferencia de sentidos que habitan en la palabra "sentido" no es fácilmente aprehensible.

\section{Sentido sensible, sentido inteligible}

Hasta el momento, debo reconocer que he hablado poco o más bien nada del sentido sensible, de los sentidos y de las sensaciones. No es que Nancy descuide la sensibilidad o le otorgue un lugar secundario en sus reflexiones sobre el arte y las artes. Nada de eso. La pregunta por el arte envuelve inmediatamente esta otra: la pregunta por la diferencia entre el sentido sensible y el sentido inteligible. En cierto modo, el "arte" no es otra cosa que la línea de compartición entre la sensibilidad y la significación, esto es, ni más ni menos, que la línea de compartición del sentido, la línea que une y separa al mismo tiempo, en un mismo gesto, los dos sentidos del sentido.

Se habrá entendido, cuando digo "el sentido del arte contemporáneo" no hago referencia únicamente a la significación de dicho arte. Es, simplemente, el sentido más accesible para muchas de las personas que nos dedicamos a la teoría. Acaso menos accesible pero no menos presente resulta la sensibilidad, la sensualidad y la sentimentalidad. Nancy, como pocos filósofos, se rinde a la exigencia de dar lugar a lo que por regla general no tiene lugar en el discurso, logrando que aquello que no pertenece de manera necesaria al orden de la significación -como sucede por ejemplo con el "arte"- pueda ser tenido en cuenta sin ser enteramente apropiado por el discurso. En rigor de verdad, es imposible que el discurso discurra sobre un motivo cualquiera sin apropiárselo, sin someterlo de inmediato a su propia lógica, la cual, como a nadie se le escapa, descansa en la autoridad del logos. Nancy es extremadamente sensible a esta imposibilidad, y allí reside, creo, la gran diferencia entre su discurso sobre el arte y el de otros filósofos más o menos conocidos y más o menos contemporáneos. Su pensamiento toca, allí donde otros pensamientos se abstienen de tocar, ya sea por prurito de racionalidad, por incompetencia, o por simple falta de sensibilidad. Pues bien, si de algo no carece esta filosofía es de sensibilidad o, si se prefiere, de un cierto tacto para tratar cuestiones que exceden el sentido sensato, sin por ello renunciar a la sensatez. Su discurso se despliega sobre el límite más allá del cual la propia discursividad pierde su poder y queda sin efecto. Ni más allá ni más acá: sino en el límite y como el límite. 
Desde ese lugar limítrofe y a veces por cierto inclasificable, se nos dice que el arte, sobre todas las cosas, da a sentir. Como ya se ha visto, lo que el arte da a sentir no pertenece exclusivamente al dominio de lo sensible. El sentido sensible y el sentido inteligible forman un "quiasmo": su disposición es la de un cruzamiento necesario, con lo cual su implicación es recíproca y constitutiva. Pero por importante que sea esta cuestión no hay que olvidar el papel que juega en todo esto la singularidad de cada sentido y la pluralidad de los sentidos. El arte da a ver, escuchar, oler, gustar y tocar. Todos los sentidos -en principio estos cinco, si bien no es seguro que sean los únicos - intervienen aquí aunque evidentemente cada uno lo hace de forma diferente. La pluralidad de las artes y la pluralidad de los sentidos son indicadores de la singularidad irreductible de cada gesto y de cada sensación, como de la circulación indefinida de las artes y los sentidos. Recordemos que hasta hace no tanto tiempo atrás, la teoría estética, con su inquebrantable voluntad clasificatoria y sistematizadora, además de ofrecer catálogos exhaustivos de las diferentes artes (las cuales a su vez se dividían entre mayores y menores, altas y bajas, etc.), proponía una correspondencia implícita o explícita entre cada uno de los sentidos y cada una de las artes. Huelga decir que en la actualidad se ha desistido de semejantes intentos de identificación y diferenciación. En parte por los innumerables problemas lógicos que supone este tipo de agrupamientos, y en parte por el rumbo que ha tomado el arte en nuestra época. Hoy, como quizás nunca antes, en la teoría y en la práctica se toma en cuenta la resonancia entre las artes. No sólo sus "correspondencias" - como da a entender Baudelaire en el soneto homónimo incluido en Las flores del mal y sobre el cual Nancy se detiene en más de una ocasión-, sino también sus incalculables combinatorias, sus interacciones y sus influencias mutuas. No hay un arte puro. De hecho nunca lo hubo, sólo que ahora resulta más fácil de comprobar que antes. En cada obra de arte hay rastros más o menos perceptibles de otras obras y otras artes, resonancias no siempre objetivas ni discursivamente comunicables. Esta es la sensación que transmiten la inmensa mayoría de las obras que se exponen en la actualidad. Del mismo modo que no hay un arte puro, vale decir que no hay un sentido puro. Aun cuando ciertas manifestaciones artísticas parezcan comprometer un solo órgano sensorial, como se supone en el caso de la música o de la pintura, por tomar estos conocidos ejemplos, lo que el arte da a sentir, sea música, pintura, literatura o danza, se siente con todo el cuerpo. La emoción que produce el arte (el placer y el displacer, el deleite y el hastío, la atracción y la repugnancia...) compromete a cada parte del cuerpo, incluidas sus partes interiores y sus partes exteriores. El arte trastoca los sentidos, sin orden ni precepto. En eso consiste la emoción o la conmoción del arte.

Nancy le reconoce un claro privilegio al tacto. Es así que puede escribir: "ningún arte que no sea un tacto claro en el umbral oscuro del sentido". ${ }^{10}$ Dado el vasto alcance que tiene la cuestión del "tacto" y del "tocar" en su obra, es imposible resumirla aquí, ni siquiera sumariamente. ${ }^{11}$ Me conformo con indicar que dicho privilegio está ligado a la idea de que el tacto, en cuanto sentido, hace sentir la proximidad y la distancia entre todos los sentidos del sentido. Tocar, que es siempre sentir y sentirse sentir, abre el sentido a los sentidos, y recíprocamente. El toque del tacto, que es siempre sentido y sintiente, es la apertura de un mundo. Si el arte es la línea de compartición entre la significación y la sensibilidad, el tacto es el sentido de esta línea. En palabras de Nancy: "El tacto es el claro / oscuro de todos los sentidos, y del sentido, absolutamente. En el tacto, en todos los tactos del tacto que no se tocan entre sí - sus tactos coloreados, trazados, melódicos, armónicos, gestuales, rítmicos, espaciantes, significantes, etc.-, los dos lados del único

10. NANCY, J.-L.: "Pintura”, El sentido del mundo (1993). Trad. J. M. Casas, Buenos Aires, La Marca, 2003, p. 129

11. Sobre esta cuestión, véase DERRIDA J.: Le toucher, Jean-Luc Nancy. Paris, Galilée, 2000. 
sentido no cesan de venir el uno al otro, accediendo sin acceder, tocando lo intocable, intacto, espaciamiento del sentido". ${ }^{12}$

El arte opera sobre el sentido separando sus lados, esto es, poniendo por un lado los sentidos sensibles o sensuales, y por otro el sentido inteligible. Esta separación no debe confundirse con una simple oposición. Se trata más bien de una compartición - palabra que propongo aquí para traducir el sustantivo francés partage, que remite a la acción y al efecto de "compartir", pero también de "dividir" y "repartir", y al que Nancy convirtió en insignia de su pensamiento. Ahora bien, esta compartición del sentido operada por el arte no ocurre sin consecuencias para el orden del discurso y de la significación. El arte, cuando emociona o conmociona, cuando sorprende, marca el "suspenso de la significación". Nancy se apresura a aclarar que la interrupción del sentido no produce una ausencia de sentido, sino más bien lo que Blanchot denomina como "sentido ausente". Pues así como el arte nos liga a la pregunta por el sentido inteligible del arte, nunca se insistirá bastante en el hecho de que el mismo arte en su venida nos desliga de toda pregunta y de todo preguntar, siendo una de sus posibilidades más elementales el abandono de la inteligibilidad en cuanto tal.

Llegados a este punto, y para no perder el hilo, cabe volver a la pregunta por el sentido del arte contemporáneo. Como se habrá adivinado, Nancy no ofrece una sola y simple respuesta. No obstante, me inclino por seguir la pista del deseo. Según él, el arte contemporáneo moviliza el deseo compartido de experimentar el desborde del sentido. Este deseo que se agita entre nosotros está directamente relacionado con el estado del mundo o, como se decía hace un instante, con su propia formación, con su puesta en forma, con la percepción que el mundo tiene de sí mismo. El desborde del sentido, en cuanto exceso que indica un más allá de la significación, es la forma actual del mundo y es eso mismo de lo que el arte actual viene a testimoniar en última instancia. Ciertamente, el arte contemporáneo no es el único testimonio del abandono del sentido, pero es a través suyo que se enciende este deseo, el cual tiene a su vez incontestables derivas éticas y políticas:

"[...] tenemos una exigencia de darnos a sentir - juntos y cada uno para síun desbordamiento del sentido. Tenemos el deseo de sentirnos según una verdad que ningún sentido satura (ni saber, ni salvación, ni justicia, etc.) y que ninguna unidad sublima.

Así, el arte contemporáneo, con su querella, saca a la luz un deseo que no es ni deseo de un objeto ni deseo de un sentido, sino deseo de sentir y de sentirse sentir - deseo de experimentarse irreductible a una significación, a un ser o a una identidad. Un deseo de gozar, sensiblemente, del hecho mismo de que no hay forma única y terminal en que este deseo tomaría fin."13

\section{Fragmento, vestigio, gesto}

Para terminar, me gustaría llamar la atención rápidamente sobre tres figuras utilizadas por Nancy en distintos momentos de su obra para aludir al arte contemporáneo. Estas son el fragmento, el vestigio y el gesto. De más está aclarar que no son las únicas. Son apenas tres figuras entre otras, que pueden leerse en el orden propuesto o en cualquier otro que se imagine puesto que no se relevan ni se excluyen entre sí.

Nancy distingue dos fragmentos, dos fragmentaciones que no deberían confundirse. Por una parte, como sabemos desde hace mucho, existe un

12. NANCY, J.-L.: "Pintura", El sentido del mundo, op. cit., p. 129.

13. NANCY, J.-L.: Chroniques philosophiques. Paris, Galilée, 2004, pp. 69-70. La traducción es mía. 
arte de la fragmentación (o bien un "arte del fragmento") que se remonta a los románticos y que luego encontraremos con diferencias notables en autores como Nietzsche, Benjamin o Adorno, por sólo nombrar a ellos. Por otra parte, como empezamos a saberlo ahora, existe la fragmentación del arte. Entre una fragmentación y otra se despliega una serie de continuidades y discontinuidades estéticas, políticas y filosóficas que son constitutivas de nuestra historia. Lo que quisiera destacar, y aquello sobre lo que Nancy insiste, es el sentido fractal del arte contemporáneo. Lo que se fragmenta o se difracta es un concepto de arte y unas prácticas artísticas que directa o indirectamente, y muchas veces sin saberlo, siguen buscando a tientas una totalidad de sentido hoy por hoy inencontrable. El fragmento indica, al mismo tiempo, tanto la posibilidad de un cierre como de una apertura hasta ahora desconocidas en el arte, en las artes. El fragmento es destello, apaga y enciende el sentido y los sentidos. De este modo queda ligado al acontecimiento: suspende el sentido, y en el mismo suspenso introduce otro sentido. La fragmentación del arte es, pues, inseparable de la fragmentación del sentido. Pero las artes no son los fragmentos dispersos de un Arte esencialmente uno, y lo mismo se puede afirmar de la relación entre los sentidos y el Sentido. Por el contrario, las artes y los sentidos son de "esencia fractal", lo que equivale a decir que existen fragmentariamente, como destellos intermitentes.

La pregunta es la siguiente: "¿podemos pensar el arte no ya como un arte del fragmento - que se queda en la obediencia de la obra en tanto acabado de una totalidad-, sino en tanto él mismo fragmentario o fractal [...]?". ${ }^{14}$ Indudablemente podemos. Con todo, no hay que escuchar en esta constatación del carácter fragmentario del arte contemporáneo un tono celebratorio ni nada que se le parezca. La fragmentación del arte es sencillamente el modo bajo el cual se renueva la posibilidad del arte y de las artes en un mundo que hace la experiencia de la fragmentación del sentido, para lo mejor o para lo peor.

"Las caídas, los deshechos, las quebraduras, los pedazos despedazados, los restos, los despojos, los recortes, las porquerías, los excrementos de los que rebosa -o los que vomita - el arte contemporáneo, el trash art, están todos puestos, depuestos y expuestos sobre el límite infinitamente delgado que separa la decadencia del caer en suerte, la pérdida del destello y el abandono del abandono mismo. [...] Entre su fracaso y su chance el arte recomienza una vez más." 15

Al anunciar un nuevo recomienzo del arte se supone que algo del arte o en el arte ha llegado a su fin. En efecto, para que el arte comience otra vez, algo del arte o en el arte ha de finalizar, pero también, y necesariamente, algo ha de quedar. Lo que queda sería un vestigio: "a la vez una huella evanescente y un fragmento casi inasible". ${ }^{16}$ La figura del fragmento se articula con aquella del vestigio. La comprensión del arte como vestigio o como resto ratifica la fragmentación del arte en el sentido indicado más arriba al mismo tiempo que dispara nuevos interrogantes. El vestigio, al igual que el fragmento, evoca el suspenso y la interrupción del sentido y los sentidos. El arte contemporáneo tiende a los extremos, a una extremidad absoluta - que sin embargo no debe confundirse con el "fin" ni con la "muerte del arte"- donde el arte deja de ser lo que es para devenir otro. En eso consiste la lógica paradójica del arte vestigial: lo que queda retiene consigo algo de lo que yo no es, y a su vez es algo completamente distinto.

14. NANCY, J.-L.: "El arte, fragmento", El sentido del mundo, op. cit, p. 186.

15. Ibid., pp. 193-194.

16. NANCY, J.-L.: "El vestigio del arte", Las Musas, op. cit., p. 113. 
Hoy el arte arrastra esta inmensa paradoja: responde de un mundo que ve agotarse una a una las grandes ideas que afirmaban la soberanía de un Sentido sin resto, incluida hasta la idea misma de Arte. El arte contemporáneo da cuenta de un mundo donde, efectivamente, el concepto tradicional de arte da claras muestras de agotamiento. Según Nancy, hay una definición de arte que abarca a todas las otras definiciones conocidas. Esta definición es la que ofrece Hegel: "el arte es la presentación sensible de la Idea". ${ }^{17}$ Según esta tesis, que con distintos lenguajes Occidente hizo suya desde los griegos hasta nosotros, el arte es la manifestación sensible de una esencia inteligible. Todo pasa una vez más por la relación problemática entre arte y sentido. Así entendido, el arte es la presentación de lo impresentable, la visibilidad de lo invisible, la imagen de la Idea. Esta idea del arte, una que todos conocemos bien puesto que atraviesa nuestra historia, es la que empieza a extenuarse junto a cada una de las ideas directrices del Sentido. A esta extenuación, Nancy la denomina retirada. "Con la retirada de la Idea", explica, "la imagen también se retira": "lejos de ser esa 'civilización de la imagen' a la que se acusa - también a ella- de crímenes cometidos contra el arte, somos más bien una civilización sin imagen, porque somos una civilización sin Idea". ${ }^{18}$

Entonces, ¿por qué continuar hablando de "arte" cuando la Idea que evoca esa palabra se encuentra en retirada? $Y$ en ese caso, ¿qué concepto le correspondería a un arte que ya no es arte en el sentido tradicional, que ya no es imagen de ninguna Idea? Se habrá notado que a pesar de todas las transformaciones anunciadas, Nancy nunca deja de hablar de "arte". Pues incluso si la definición occidental de arte está excedida, y en cierto modo ya estamos más allá de ella, aún es menester discutir con ella. No hay que perder de vista que esta discusión o esta querella no es sólo filosófica, sino también, y principalmente, artística. Ahora bien, ¿qué concepto para el arte de nuestro tiempo? He aquí un problema dado que no hay concepto, en sentido estricto, para este arte. Lo que hay o lo que queda es vestigio. El vestigio no remite a nada, es "casi nada", apenas lo que queda del sentido una vez que el Sentido se retira. Nancy va a buscar el sentido de la palabra vestigio a la teología y a la mística para luego aplicarlo al arte contemporáneo. No en vano puede escribir: "el arte es humo sin fuego, vestigio sin Dios, y no presentación de la Idea. Fin del arte-imagen, nacimiento del arte-vestigio". ${ }^{19}$

Hay que insistir en esto: el arte-fragmento o el arte-vestigio, por diferente que sea del arte-imagen de otros tiempos, sigue siendo arte. Y esto es así, más que por una simple razón de tradición o de costumbre, por el hecho de que algo del arte, en el arte, resiste. Hay un "gesto del arte" que resiste a lo largo de la historia. Desde la pintura rupestre hasta la instalación, la performance y el video de nuestros días, un gesto se repite, diferentemente cada vez, a través del tiempo: el gesto del arte, el gesto del artista. Nancy vuelve una y otra vez al gesto, a la palabra "gesto", para decir que lo que llamamos así no pertenece al orden del decir, ni exclusiva ni principalmente. En la conferencia "El arte hoy", que cité al comienzo, se explica que toda obra artística, sea cual sea la intención del artista, compromete algo distinto a la significación, y que allí reside propiamente el gesto de la obra. Cito nuevamente la conferencia: “¿Qué es un gesto? Un gesto no es ni un movimiento ni el trazado de una forma. Un gesto, de manera general, quiero decir en la vida, se podría decir que es el acompañamiento de una intención pero que, en sí mismo, permanece extraño a la intención. [...] El gesto es un dinamismo sensible que precede, que acompaña o que sucede al sentido o a la significación, es sentido sensible". No hay arte ni artista ni obra sin gesto. 
Tal es la marca del arte desde su nacimiento hasta la actualidad pasando por todas y cada una de sus innumerables transfiguraciones. El gesto es del orden de la moción, de lo que mueve y conmueve, en definitiva, de lo que toca. Quizás ahora se entienda mejor porque un enunciado como "el arte da a sentir" es válido en todos los tiempos. El gesto sensible resiste al paso del tiempo. Por eso mismo Nancy define el gesto a la vez como lo "mínimo" y lo "esencial" del arte, vale decir, como el límite extremo al que se puede reducir el arte antes de que deje de ser lo que es para transformarse en otra cosa. En este sentido, se puede decir que el gesto es lo irreductible del arte. Henos aquí una vez más en los confines de lo artístico, muy cerca del fragmento y del vestigio.

Todo arte, todo artista y toda obra, en todas las épocas, instauran un gesto. Lo que sugiere Nancy es que "la situación del arte hoy nos permite (o nos obliga a) volvernos atentos a este gesto que es a la vez lo mínimo del arte pero quizás también lo esencial".

Todo sucede como si el histórico "gesto del arte", a fuerza de repetición y resistencia, hoy se hubiera convertido en "arte del gesto". Muchas veces, el conjunto de prácticas que solemos identificar como "arte contemporáneo" no son otra cosa más que gestos. Pensemos si no en el famoso urinario de Duchamp, cuya exhibición es considerada por muchos críticos e historiadores el acto fundacional de dicho arte. ¿Qué fue eso si no un gesto? Un gesto en apariencia incomprensible pero no del todo ajeno a la comprensión. Pues el gesto, como se dijo antes, es sentido sensible que acompaña al sentido inteligible. Nancy se lo figura como "un signo, pero un signo en el sentido de una señal", un signo en el sentido de la palabra alemana Wink - tan intraducible al francés como al castellano-: "una pequeña seña, como para saludar, un gesto de inteligencia, una guiñada de ojo".

Fragmento, vestigio, gesto: tres nombres posibles para indicar el sentido del arte contemporáneo. Cada uno de ellos constituye una figura autónoma, con una inflexión propia y característica. Cada uno traza un sentido y se orienta en una dirección particular. No obstante, es imposible dejar de notar que ellos mismos y los sentidos que trazan tienden a tocarse. Convergen en la extremidad del extremo donde el arte finaliza y comienza una vez más. Hacen sentido allí donde el sentido se deshace para dar lugar a una pluralidad de sentidos. El sentido, lo mismo que el arte, es "singular plural" o no es nada. Por lo menos nada de este mundo, nada que pueda responder o testimoniar de nuestro mundo actual. Si "el arte es siempre al menos, sea el que sea, algo que tiene relación con el mundo como tal, con la totalidad del mundo como lugar y medio de la existencia"20, entonces la tarea que se impone en adelante a quien se proponga relanzar la pregunta por el sentido del arte contemporáneo no puede ni debe prescindir de un pensamiento y una experiencia del mundo y de la existencia, vale decir, de lo que somos hic et nunc, aquí y ahora. 